\title{
Analysis of Household Financial Investment Behavior Based on Life Cycle
}

\author{
Xiaohui Chen*, Bei Qin, Lei Zhang and Zhixin Chen
}

School of Finance, Nanjing University of Finance and Economics, Nanjing 210030, China;

* Corresponding author

Keywords: Life cycle; Family Financial Investment; House property; Household income.

Abstract. In recent years, the field of family finance has always been a focus of research. Family financial investment involves not only the optimization of household asset allocation but also the operation of macroeconomics. Turning to family finance, this paper focuses on the characteristics and influencing factors of household financial investment behavior in the life cycle. Specifically, the results indicate that from the perspective of the characteristics of household financial investment behavior, the participation of China's financial assets investment is low on the whole, and investors prefer to riskless assets. Further analysis suggests that house property and household income as main variables have a positive impact on financial assets investment. As age increases, on the one hand, the impact of house property on financial investment decreases first and then increases, and has a greater impact on risky assets. On the other hand, family income has a greater impact on financial assets with the increase of the age, and has a greater impact on risk-free assets.

\section{Introduction}

Along with continuous development of capital market and the constant broadening and deepening of family participation in financial investment, many scholars have started to shift their research orientation from the macroeconomic level to the emerging field of family finance. Furthermore, most families want to use financial instruments to achieve optimal asset allocation. As a basic unit of social economic operation, household financial investment behavior affected by policy and economic operation, has huge impacts on the formulation and adjustment of policies and economic operation. Based on the research of family financial investment behavior, we can grasp the general changes of family financial asset structure in different life cycles and infer the financial investment preferences of people of different ages. Moreover, we may get principal influence factors according to family financial investment. In turn, it provides scientific guidance for the family financial assets allocation and offers a reasonable basis for policy adjustment.

Judging from the investment situation of the families around us, most families are more inclined to invest in risk assets in the early stage of establishment. However, as the age increases, many families will gradually decrease the holding of risky assets to increase alternative stable investment. Indeed, investors at different stages of life will have different investment demands and choices. Then, what are the characteristics of the financial assets allocation in the life cycle? What are the influencing factors? How is it affected? These are all important issues to this paper.

\section{Literature Review}

In recent years, family finance has emerged as an emerging research direction. Scholars have conducted empirical analysis through micro-data collected, and have obtained a series of research results. Early studies, such as Markowitz (1952), have proposed a portfolio theory of risk aversion. According to this theory, investors will diversify their total assets into risk-free assets and market portfolios based on different risk preferences. Since then, related literature by Samuelson (1969) and Merton (1969) have extended previous model from single period to multi periods based on the theory of Markowitz's portfolio, and concluded that age and wealth accumulation are independent of portfolio selection. However, due to that family investors are affected by the life cycle and different investment needs correspond to different investment goals over the life cycle, the age change is one of the important factors affecting family 
financial investment decision-making. Moreover, a large number of empirical results also confirm the family financial investment behavior has a life cycle.

Milligan found that the portfolio share of financial assets increased considerably with the increase of the age, while the risk tolerance level seems to slightly decline. Along with the increase of the age, related families prefer to choose assets that are more liquid and less risky. Investment in risky assets has been greatly reduced after retirement, while the share of riskless assets has increased [1]. Wu Weixing et al. conducted an empirical analysis and suggested that the household investment of the residents has a life cycle characteristic to a certain extent, but the degree of influence differs in various assets [2]. Through descriptive statistics and empirical analysis, Chai Shijun tested the impact of age and age structure on household financial asset allocation using the sample data of the 2011 Family Finance Survey. The results show that Chinese residents are affected by age when making investment choices. Specifically, older people are less likely to participate in risky assets than young people, that is, family age structure changes has negative relation with risk market participation [3]. Li Lifang and Wang Cong also pointed out that the degree of risk aversion is positively correlated with the proportion of the elderly [4].

The above literature indicates that family financial allocation fluctuates over time. Different age groups have different risk aversion, and there are different choices in the allocation of risk-free assets and risk assets. As a whole, it seems that risk assets first increase and then decrease, while riskless assets decrease first and then increase with the increase of the age. Zheng Dandan carried on the analysis to study household asset allocation behavior from the perspective of total financial assets and allocation structure. As a result, the family financial asset allocation does have life cycle characteristics [5]. Wu Weixing found that investors would increase the holding of family venture capital as the number of housing increases, and housing may be positively correlated with the allocation of financial assets [6]. Song Wei (2016) introduced labor income into the model of household asset allocation, and found that if expected labor income increases in the future, investors will increase the proportion of risk assets accordingly. The increase in income risk will directly affect the residents' holdings on risk assets [7].

The empirical analysis of the above literature confirms that the family investment in China has life cycle effect. This paper focuses on not only the characteristics of family financial investment in the life cycle, but also hopefully contributed to the influencing factors of family financial investment behavior in the life cycle. A stream of literatures outlines that the main factors affecting the allocation of household assets are household income, house property, financial knowledge, risk aversion, and education. Among them, what we are most concerned about is the two factors of property and income.

\section{Status Analysis of Chinese Household's Financial Investment Behavior Under the Perspective of Life Cycle}

\subsection{Status analysis of family investment behavior from the whole perspective.}

With the development of China's economy, the total assets of Chinese households have increased rapidly. Table 1 displays that China's per capita total assets reached 761,000 yuan in 2013 and by 2016 it amounted to over 1.034 million yuan. We can also find that house property accounts for the highest proportion of total assets, and the average annual growth rate of that is $22.6 \%$, while the fraction of financial assets is small, with an average annual growth rate of $10.0 \%$.

Table 1 Household assets and proportion (yuan)

\begin{tabular}{ccccccc}
\hline Assets & \multicolumn{2}{c}{2013} & \multicolumn{2}{c}{2015} & \multicolumn{2}{c}{2016} \\
\hline Total assets per household & 76.10 & $100.0 \%$ & 92.90 & $100.0 \%$ & 103.40 & $100.0 \%$ \\
House property & 47.41 & $65.3 \%$ & 60.66 & $68.8 \%$ & 71.14 & $65.3 \%$ \\
Financial assets & 9.82 & $12.9 \%$ & 10.59 & $11.4 \%$ & 11.89 & $11.5 \%$ \\
\hline
\end{tabular}

Table 1 reports that the scale of household assets has been soaring. From the perspective of changes in house property, the total value of house property has increased rapidly every year, and the proportion of house property in total household assets has also increased with a steady rate. Considering financial assets, although the total value of family financial assets has gradually increased, the fraction in total assets has 
declined. The aforementioned phenomena show that the house property may have a certain crowding out effect on the allocation of financial assets.

\subsection{Status analysis of household financial investment behavior by age group.}

As follows, this section presents descriptive statistics for related data to exhibit the family's investment in different age groups. The data is from the 2011 Family Finance Survey sample of China Household Finance Investigation and Research Center of Southwestern University of Finance and Economics.

Table 2 Per capita financial assets and proportion of households (yuan)

\begin{tabular}{cccccccccccc}
\hline Assets & \multicolumn{2}{c}{25 or Less } & \multicolumn{2}{c}{$25-35$} & \multicolumn{2}{c}{$35-55$} & \multicolumn{2}{c}{$55-65$} & \multicolumn{2}{c}{65 or More } \\
\hline Average financial assets & 77454 & $100 \%$ & 79419 & $100 \%$ & 52772 & $100 \%$ & 42493 & $100 \%$ & 34784 & $100 \%$ \\
& & & & & & & & & & \\
Deposit & 53626 & $69.24 \%$ & 38180 & $48.07 \%$ & 26011 & $49.29 \%$ & 23702 & $55.78 \%$ & 25742 & $74.01 \%$ \\
Stock & 6833 & $8.82 \%$ & 19010 & $23.94 \%$ & 12863 & $24.37 \%$ & 7432 & $17.49 \%$ & 3198 & $9.19 \%$ \\
Bond & 0 & $0.00 \%$ & 863 & $1.09 \%$ & 315 & $0.60 \%$ & 370 & $0.87 \%$ & 1341 & $3.86 \%$ \\
Fund & 1870 & $2.41 \%$ & 2594 & $3.27 \%$ & 2159 & $4.09 \%$ & 1612 & $3.79 \%$ & 1567 & $4.50 \%$ \\
Derivatives & 0 & $0.00 \%$ & 0 & $0.00 \%$ & 78 & $0.15 \%$ & 1 & $0.00 \%$ & 0 & $0.00 \%$ \\
Non-renminbi assets & 1104 & $1.43 \%$ & 662 & $0.83 \%$ & 277 & $0.52 \%$ & 476 & $1.12 \%$ & 97 & $0.28 \%$ \\
Gold & 292 & $0.38 \%$ & 561 & $0.71 \%$ & 177 & $0.34 \%$ & 280 & $0.66 \%$ & 14 & $0.04 \%$ \\
Cash & 6282 & $8.11 \%$ & 11091 & $13.97 \%$ & 4913 & $9.31 \%$ & 3181 & $7.49 \%$ & 2041 & $5.87 \%$ \\
Borrowing & 7447 & $9.61 \%$ & 6457 & $8.13 \%$ & 5980 & $11.33 \%$ & 5439 & $12.80 \%$ & 784 & $2.25 \%$ \\
\hline
\end{tabular}

Table 2 reveals that under the age of 25 and 25-35, the per capita financial assets are the largest, respectively, 77454 yuan and 79419 yuan. With the increase of the age, the holding of per capita financial assets gradually declined. The peak value of per capita deposits is 53626 yuan, which appears below the age of 25. The holdings of bank deposits and the proportion of financial assets increase first and then decrease with the increase of the age. The peak value of stock assets is 19,010 yuan in the 25-to-35 age span. Also, the fraction of per capita stocks and the corresponding proportion in financial assets have increased first and then decreased with the increase of the age. Similarly, so it is the cash assets. The peak of bond holdings appears in the 65-year-old and the fund holdings are apparently high in the 25-to-35 age group. The dynamic change of lending, gold, derivatives, and non-RMB assets is modestly irregular at different ages.

\section{Empirical Research}

From the aforementioned research, we can find that house property and household income may have on financial investment behavior throughout the life cycle. Therefore, we will research the impacts of house property and household income on household investments from the perspective of different age groups.

\subsection{Model.}

This section focuses on the impacts of house property and household income on household financial investments. Therefore, a multiple linear regression model is defined as followed:

$$
Y=C+\alpha X_{1}+\beta X_{2}+u
$$

where $Y$ is the amount financial assets. During the research, we decompose financial assets into risk assets and risk-free assets and let $Y 1$ and $Y 2$ denote risk assets and risk-free assets, respectively. $X_{1}$ represents the house property, $X_{2}$ means household income, and $u$ represents random interference.

\subsection{Data and variable description.}

The data involved in this paper can be found from the 2011 Family Finance Survey sample of China Household Finance Investigation and Research Center of Southwestern University of Finance and Economics. The questionnaire included 8438 household samples and 29,324 individual samples. In terms of variable processing, we logarithmically treat the independent and dependent variables. The corresponding regression results are shown in Section 4.3. 


\subsection{Regression results.}

Table 3 reveals the factors that influence the household's risk investment. From the regression results, we can find the $\mathrm{p}$ value corresponding to the $\mathrm{F}$ value is small, indicating that the associated relation is generally linear. The p-values of the $\alpha$ coefficient and the $\beta$ coefficient for most age groups are less than 0.01 , indicating that they have a significant influence to dependent variable (risk asset). The p-value of the $\beta$ coefficient above 65 years old is greater than 0.05 , indicating that the coefficient is not significant, and the p-value of the $\beta$ coefficient below 25 years old is too small to pass the significance test of the coefficient.

Table 3 Model One Linear Regression Results (risk investment, Y1)

\begin{tabular}{cccccccccc}
\hline & $\mathrm{c}$ & $\mathrm{p}$ & $\alpha$ & $\mathrm{p}$ & $\beta$ & $\mathrm{p}$ & $\mathrm{R}^{\wedge} 2$ & $\mathrm{~F}$ & $\mathrm{p}$ \\
\hline 25 or less & -2.1778 & 0.5464 & 0.7799 & 0.0081 & 0.1349 & 0.4503 & 0.1860 & 5.5975 & 0.0065 \\
$25-35$ & 1.5167 & 0.1496 & 0.2426 & 0.0033 & 0.4858 & 0.0000 & 0.1924 & 38.2314 & 0.0000 \\
$35-55$ & -0.3645 & 0.5429 & 0.4525 & 0.0000 & 0.4245 & 0.0000 & 0.2938 & 178.2482 & 0.0000 \\
$55-65$ & -3.8832 & 0.02233 & 0.5112 & 0.0000 & 0.5316 & 0.0037 & 0.2801 & 41.2510 & 0.0000 \\
65 or more & -0.8635 & 0.6510 & 0.5218 & 0.0000 & 0.2480 & 0.2064 & 0.2750 & 18.7793 & 0.0000 \\
\hline
\end{tabular}

Table 4 reveals the factors that influence the risk-free investment of households. From the regression results, we can get that $\mathrm{p}$-value corresponding to $\mathrm{F}$ is small, indicating that the linear relationship of the model is generally significant. The $\mathrm{p}$ value of the coefficient $\beta$ below 25 years old is 0.6654 , and the effect is not significant. The p-values of the $\alpha$ coefficient and the $\beta$ coefficient of other age groups are small, indicating that the explanatory variables have a significant influence on the dependent variable (riskless assets).

Table 4 Model Two Linear Regression Results (risk-free investment, Y2)

\begin{tabular}{cccccccccc}
\hline & $\mathrm{c}$ & $\mathrm{p}$ & $\alpha$ & $\mathrm{p}$ & $\beta$ & $\mathrm{p}$ & $\mathrm{R}^{\wedge} 2$ & $\mathrm{~F}$ & $\mathrm{p}$ \\
\hline 25 or less & 0.8794 & 0.6512 & 0.5220 & 0.0000 & 0.1918 & 0.6654 & 0.1667 & 10.6021 & 0.0001 \\
25-35 & 0.8844 & 0.1291 & 0.2996 & 0.0000 & 0.4263 & 0.0000 & 0.1808 & 104.2763 & 0.0000 \\
35-55 & -0.7056 & 0.0164 & 0.3477 & 0.0000 & 0.5008 & 0.0000 & 0.2288 & 508.1423 & 0.0000 \\
55-65 & -1.5739 & 0.2651 & 0.4024 & 0.0000 & 0.5062 & 0.0000 & 0.2812 & 281.3239 & 0.0000 \\
65 or more & -2.0523 & 0.0000 & 0.4471 & 0.0000 & 0.6464 & 0.0000 & 0.3651 & 265.8524 & 0.0000 \\
\hline
\end{tabular}

From the above regression analysis, we can find that both $\alpha$ (house property) coefficient and $\beta$ (family income) coefficient are strictly positive. Therefore, the house property and household income are positively correlated with financial assets.

\section{Conclusion}

The research in this paper shows that that family financial investment behavior has life cycle characteristics. Furthermore, house property and household income have a significant impact on financial asset investment. Consequently, if investors carry on asset allocation in the life cycle, they must reasonably consider both housing and household income as crucial influencing factors.

Household income has more and more influence in financial investment with the increase of the age. Especially in retirement, the sharp decline in income has the greatest impact on the allocation of financial assets. It is proved that, to a certain extent, Chinese families are more accustomed to treating current income as the basis for investment decisions. In fact, when investing in asset allocation, family investors need to think over not only the impact of current income on household consumption, but also the impact of future income on consumption and demand. Due to this point, feasible and pragmatic investment objectives can be established throughout the life cycle, aiming at maximizing the utility of the entire life cycle. 
The research shows that house property not only promotes the allocation of financial assets, but also has a more significant impact on risky assets. Therefore, family investors should beware of excessively aggressive investment behavior caused by property premiums when making asset allocations. The premium of housing does bring about the growth of wealth, but the wealth of growth may be not always realized or realized in time.

Housing and household income will promote residents' investment in financial assets, illustrating that the growth of residents' wealth is conducive to expanding and deepening the participation of financial markets. Therefore, on the one hand, the government needs to improve the construction of financial markets, improve the rules and regulations of financial markets, and increase the breadth and depth of financial development. On the other hand, the government needs to improve the level of economic development, increase the income of residents, and strengthen the positive impact of the wealth effect on residents' investment.

\section{References}

[1]. Milligan K. Life - cycle asset accumulation and allocation in Canada[J]. Canadian Journal of Economics, 2005, 38(3): 1057-1106.

[2]. Wu Weixing, Yi jinran, ZHEN jianming. Chinese household investing structure: based on life circle, wealth and housing analysis [J].Economic Research, 2010, 45(S1):72-82.

[3]. Chai Shijun. The effect of household financial asset allocation under social internet and age structure.[D]Jinan University.2016.

[4]. Li Lifang, Wang Cong. Life circle, population structure and residential investment structure-evidence from Chinese household research (CHFS) [J]. Journal of South China Normal University, 2015(04):13-18.

[5]. Zheng Dandan. The effect of residential asset allocation [D]. Guangxi University, 2016.

[6]. Wu Weixing, SHEN Tao, JIANG Tao. Does real estate squeeze out risky financial asset in household allocation?--based on micro data empirical analysis [J].Scientific decision 2014(11):52-69.

[7]. Song Wei. Labor income and Chinese country household asset allocation research.[D].Shang Hai Jiaotong University, 2016. 